\title{
К ВОПРОСУ О РЕАЛИЗАЦИИ В РОССИЙСКОЙ ФЕДЕРАЦИИ КОНЦЕПЦИИ «ИСПОЛНИТЕЛЬНОГО ФЕДЕРАЛИЗМА»
}

\begin{abstract}
Аннотация: Настоящая статья посвящена вопросам совершенствования федеративных отношений в России в аспекте оптимизаичи взаимодействия федеральных и региональных исполнительных органов власти. Предлагается использование при модернизации схемь взаимоотношений по линии исполнительной власти положительно зарекомендовавщей себя за рубежом кониепции исполнительного федерализма с учетом отечественных национально-государственных традииий. Внедрение принцииа исполнительного федерализма в России позволит наполнить правовой статус субъектов Федерации реальным содержанием.

Ключевые слова: исполнительный федерализм, дечентрализачия, разграничение полномочий, Германия, исполнительная власть, Австрия, взаимодействие, контроль, субъект Федерации, передача полномочий.
\end{abstract}

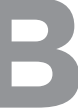

современной теории федерализма к основным признакам федеративного государства, в первую очередь, относят наличие, как минимум двух уровней государственной власти, каждый из которых обладает определенной степенью автономии ${ }^{1}$. Иными словами, региональная публичная власть - уровень субъектов федерации - должна быть самостоятельной в установленных федеральной конституцией рамках. Именно самостоятельность и независимость государственной власти субнационального уровня является свидетельством ее реальности и самодостаточности, а, значит, существования реального, а не мнимого федерализма.

Причин федерализации современных государств немало. И в каждом конкретном случае указанные причины или их сочетание уникальны ${ }^{2}$. Применительно к России основными предпосылками становления современного федерализма в начале 90-хгг. ХХ века были: с одной стороны, неизбежность сохранения национального подхода при структурировании федерации, характерного для советского периода нашей государственности, и, с другой, сложнейшая политическая конъюнктура, грозившая распадом единого государства (парад «суверенитетов» и т.п.). Именно с целью согласования указанных обстоятельств и преодоления негативных тенденций государственноправового развития Конституция 1993 года закрепила действующую модель федерализма.

В настоящее время российский федерализм (начиная с начала 2000-х гг.) движется в сторону сильнейшей централизации государственной власти, степень реализации которой дает основание некоторым исследователям говорить о существовании в нашем государстве

\footnotetext{
${ }^{1}$ См., например: Андерсон Дж. Федерализм: введение. - М.: Издательство «Экономика», 2009. С. 10-11.

2 Там же. С. 15.
}

«унитарного федерализма»3. Соответственно, роль субъектов Российской Федерации в компетенционном и организационном аспектах нивелирована до необходимости копирования федерального законодательства на региональном уровне и исполнения части федерального законодательства ${ }^{4}$.

Указанные обстоятельства ставят перед отечественной правовой наукой задачу поиска перспективных форм трансформации федеративных отношений, которые должны обеспечить качественное развитие российской государственности. На сегодняшний день общепризнанна роль сравнительного правоведения как средства научного познания. «...Сравнительное правоведение как метод обладает более широким спектром типовых решений, чем национально замкнутая правовая наука. И прежде всего потому, что решения, содержащиеся в правовых системах мира, уже в силу объективной необходимости более разнообразны и богаче по содержанию, чем те, которые может разработать за время своей короткой жизни ограниченный рамками своей национальной системы юрист, пусть даже

\footnotetext{
${ }^{3}$ См., например: Люхтерхандт О. Россия на пути к имитации федерализма //Казанский федералист. - 2005. - № 2-3(1415). URL: http://www.kazanfed.ru/publications/kazanfederalist/ n14-15/29/; Казаков А. 10 лет Конституции и перспективы федерализма в России //Российская газета - Федеральный выпуск. № 3376 от 30 декабря 2003 года; Бланкенагель А. В поисках исчезнувших исключительных полномочий субъектов Российской Федерации //Сравнительное конституционное обозрение. - 2007. - № 1. - С. 153-162 и др.

${ }^{4}$ Ярким примером вышеизложенного является анализ количественного соотношения территориальных органов федеральных исполнительных органов государственной власти и региональных исполнительных государственных органов на уровне субъектов Российской Федерации. Так, в Республике Северная Осетия-Алания число территориальных органов федеральной власти заметно превосходит число республиканских исполнительных структур (54 и 46 соответственно).
} 
Государственные институты и правовые системы

обладающий богатым воображением. Сравнительное правоведение, подобно «школе правды», расширяет и обогащает «набор решений» и предоставляет критически настроенному исследователю возможности найти «более оптимальное решение» для данного времени и места.»5.

В этой связи, целесообразно в контексте взаимоотношений исполнительной власти различных уровней в федеративном государстве исследовать зарубежный опыт. Однако следует «проверять не только то обстоятельство, оправдало ли себя на практике в своей стране иностранное решение, признанное оптимальным, но и его приемлемость для правовой системы данной страны. Может оказаться, что разработанные и применяемые в какой-либо стране решения не могут быть перенесены в собственную правовую систему по крайней мере в неизменном виде, так как в ней иная система судопроизводства, на власти возложено выполнение других задач, разные модели управления народным хозяйством или же по каким-либо особым соображениям социальная среда, в которой должно функционировать заимствованное за рубежом решение, отличается от иностранной.» ${ }^{6}$.

Вследствие этого, приемлемость рецепции положительного зарубежного опыта должна оцениваться сквозь призму отечественных национально-исторических традиций и сложившихся современных предпосылок, свидетельствующих о готовности государства и общества к внедрению соответствующих правовых механизмов.

В данном контексте интерес представляет закрепленный в законодательстве некоторых федеративных государств принцип «исполнительного федерализма» 7

\footnotetext{
${ }^{5}$ См.: Цвайгерт К., Кёти Х. Введение в сравнительное правоведение в сфере частного права: В 2-х тт. - Том I. Основы: Пер. с нем. - М.: Международные отношения, 2000. С.28.

${ }^{6}$ Там же. С. 30.

${ }^{7}$ Следует заметить, что категория «исполнительный федерализм» в современной науке конституционного права трактуется неоднозначно, более того, часть исследователей крайне негативно относится к ее роли в структуре федеративных отношений. Одно из пониманий концепции исполнительного федерализма связано с практикой федеративных отношений в Канаде. В данном государстве существует организационная и компетенционная обособленность федеральных и региональных исполнительных органов (дуалистический принцип разграничения компетенции). Сфера совместных полномочий незначительна, а кантоны не исполняют федеральные законы. Соответственно, в Канаде разграничение исполнительной компетенции полностью соответствует разграничению законодательной компетенции. Вместе с тем, поскольку в Конституции Канады имеется почти полное отсутствие внимания к вопросу о межгосударственных отношениях, данный процесс регулируется серией неофициальных межправительственных соглашений. В послевоенный период указанная политика получила название исполнительного федерализма. Большинство межгосударственных отношений проводится непосредственно премьер-министрами или министрами и иными должностными лицами, находящимися под их непосредственным контролем.
}

Представляется, что наиболее удобным в концептуальном и институциональном разрезах для сравнительного исследования федеративных отношений является опыт таких государств, как Германия и Швейцария. В частности, в научной литературе вполне обосновано отмечается, что Федеративная Республика Германия и Российская Федерация имеют немало схожего. Так, в обеих странах используется во многом идентичная схема разграничения предметов ведения и полномочий: в конституциях указанных государств определены исключительные полномочия федерации и совместные (конкурирующие) полномочия федерации и ее субъектов. Оставшиеся без указания полномочия считаются компетенцией субъекта федерации (остаточный принцип). Кроме того, в России, как и в Германии, законодательная власть, по сути, принадлежит федерации. Однако «поскольку в Российской Федерации распределение предметов ведения и полномочий происходит в целом без конкретизации по существующим ветвям власти, то распределение исполнительной компетенции осуществляется подобно распределению законодательной компетенции, т.е. федерация обладает также значительным перевесом и в области исполнительной власти.» ${ }^{8}$. Немаловажным является также и тот факт, что общей тенденцией обеих стран в государственно-правовом развитии является «движение

Федеральное Правительство, как и большинство провинциальных правительств, имеет отдельные министерства, ответственные за межгосударственные отношения. Многочисленными являются заседания, проводимые на уровне между государственных служащих федеральных и провинциальных правительств, в первую очередь, по вопросам реализации соглашений на высоком уровне. Хотя Конституция наделяет провинции исключительными полномочиями по большинству вопросов социальной политики, Федеральное правительство, обладая финансовым преимуществом, оказывает существенное влияние на их реализацию. Данное обстоятельство означает, что фактически исключительные полномочия провинций являются предметами совместного ведения. - См. подробнее: Boadway R., Watts R. Fiscal Federalism in Canada.- Institute of Intergovernmental Relations Queen's University Kingston, Ontario Canada, 2000. URL: http://www.fiscalreform.net/library/pdfs/fiscal_federalism_in_canada.pdf.

В отличие от указанной модели европейский федерализм (прежде всего, ФРГ, Швейцария, Австрия) отличается существенной спецификой. Как справедливо указывает Н.А. Филиппова, «конституционная модель разграничения полномочий в европейских федерациях существенно отличается от канадской - можно предположить, что и исполнительный федерализм в Европе иной.». - См.: Филиппова Н.А. Исполнительный федерализм в России: выбор между внепарламентской и парламентской моделями обеспечения интересов субъектов Федерации /Конституционное и муниципальное право. - 2008. - № 15. //СПС «КонсультантПлюс». Именно европейская модель исполнительного федерализма избрана нами для осуществления сравнительного анализа.

${ }^{8}$ См.: Саленко А.В. Федерализм в России и Германии: Сравнительный анализ: Автореферат диссертации на соискание ученой степени кандидата юридических наук. - М., 2002. С. 21. 


\section{Право и политика $2(158) \cdot 2013$}

к «унитарной федерации». Главными признаками унитаризации современной Российской Федерации являются: 1) концентрация законодательной компетенции в руках федерального центра; 2) сужение договорной практики регулирования федеративных отношений: 3) существование двух властных вертикалей: законодательных и исполнительных органов власти; 4) сосредоточение всей политической жизни на федеральном уровне.»ๆ.

Указанная выше необходимость учета при оценке зарубежного федеративного опыта существующих политико-правовых условий развития российского федерализма предполагает акцентирование внимания на следующих обстоятельствах:

- наличие конституционного принципа единства органов исполнительной власти в Российской Федерации в рамках предметов ведения Федерации и предметов совместного ведения Федерации и ее субъектов (часть 2 статьи 77 Конституции 1993 года $\left.{ }^{10}\right)$;

- новый порядок наделения полномочиями высших должностных лиц субъектов Российской Федерации региональными законодательными (представительными) органами по представлению Президента России, в том числе возможность роспуска местных парламентов в случае двухкратного неутверждения представленной кандидатуры;

- отношения субординации высшего должностного лица с Президентом России (Постановление Конституционного Суда Российской Федерации от 21 декабря 2005 года № 13-П $\left.{ }^{11}\right)$;

- право Президента РФ контролировать эффективность деятельности органов исполнительной власти субъектов Российской Федерации ${ }^{12}$;

- полномочия высшего должностного лица субъекта Российской Федерации по организации взаимодействия и координации деятельности региональных органов исполнительной власти и территориальных органов федеральных органов исполнительной власти ${ }^{13}$ и др.

Что касается концепции «исполнительного федерализма», то она нашла свое закрепление в законодательстве

\footnotetext{
9 Там же. C. 6-7.

${ }^{10}$ CM.: URL: http://www.constitution.ru.

${ }^{11}$ См.: Российская газета - Федеральный выпуск. - № 3963 от 29 декабря 2005 года.

${ }^{12}$ См.: Указ Президента РФ от 28 июня 2007 года № 825 «Об оценке эффективности деятельности органов исполнительной власти субъектов Российской Федерации» //Собрание законодательства Российской Федерации. - 2007. - № 27, ст. 3256.

${ }^{13}$ См.: Указ Президента РФ от 2 июля 2005 года № 773 «Вопросы взаимодействия и координации деятельности органов исполнительной власти субъектов Российской Федерации и территориальных органов федеральных органов исполнительной власти» // Российская газета. 8 июля 2005 г. № 147.
}

ряда современных государств (ФРГ, Швейцария, Австрия и др.). Суть данного принципа в том, что согласно конституции законодательные полномочия сосредоточены на уровне федерации, а компетенцией по исполнению федеральных законов, за установленными исключениями, наделены органы власти субъектов федерации (например, статьи 70-75, 83-84 Основного закона ФРГ, статья 46 Конституции Швейцарии). Для исполнительного федерализма характерна интегрированная модель распределения полномочий по вертикали, в соответствии с которой «..некоторые вопросы отданы в исключительное ведение одного уровня власти (например, оборона - федеральному правительству), но большинство предметов ведения относится к совместной компетенции, когда центральное правительство принимает рамочное законодательство, а субъекты федерации могут его дополнять (не вступая в противоречие) собственным законодательством.» ${ }^{14}$.

Приведенная схема интегрированной модели разграничения предметов ведения и полномочий со всей наглядностью иллюстрирует принципиальное отличие соответствующих положений российской Конституции от аналогичных зарубежных основных законов. Так, хотя Конституция 1993 года и закрепила широкий круг вопросов совместной компетенции, в то же время пределы федерального законодательного регулирования в данной области задаются самим федеральным законодателем при принятии конкретного закона. Иными словами, если в Российской Федерации разграничение предметов ведения между федерацией и ее субъектами носит паушальный характер, то, например, в Германии механизм распределения государственных полномочий непосредственно связан с разделением ветвей власти, распределением функций их реализации за конкретным уровнем государственной власти ${ }^{15}$.

Исполнительный федерализм основан на иерархических отношениях между Федерацией и ее субъектами по вопросам исключительного ведения Федерации. Компетенция, закрепленная за Федерацией, обычно ограничена законодательными полномочиями. Исполнение законодательных актов входит в остаточные полномочия регионов ${ }^{16}$.

В Федеративной Республике Германия Основной закон содержит запрет «смешанного управления», в соответствии с которым не допустимы совместное осуществление Федерацией и землями планирования, управ-

\footnotetext{
${ }^{14}$ См.: Андерсон Дж. Указ. соч. С. 32, 34.

${ }^{15}$ См., например: Саленко А.В. Указ. соч. С. 20.

${ }^{16}$ См., например: Фляйнер T. Швейцария: субсидиарность, этническое и культурное разнообразие /Материалы Международной научно-практической конференции «Федерализм: российское и швейцарское измерения» (Казань, 22-23 июня 2001года). URL: http://www.kazanfed.ru/actions/konfer2/.
} 
Государственные институты и правовые системы

ления и принятия решений, если иное Конституцией не предусмотрена передача соответствующих полномочий Федерации ${ }^{17}$. Так, в частности, в соответствии с Основным законом земли исполняют федеральные законы, как свои собственные, и самостоятельно регулируют создание ведомств и процедуры управления ими (статьи 83 и 84). Что касается законодательных полномочий, то земли имеют право законодательствовать в той мере, в какой Основной закон не предоставляет законодательные полномочия Федерации (статья 70). При этом в сфере исключительной законодательной компетенции Федерации земли обладают законодательными полномочиями лишь по специальному управомочию федерального закона, а в рамках конкурирующего законодательства земли имеют право законодательствовать лишь в случаях, если Федерация не пользуется посредством закона своей законодательной компетенцией (статьи 71 и 72).

Можно выделить следующие типы распределения исполнительной компетенции в Германии: 1) исполнение федеральных законов землями как своих собственных (статьи 83, 84 Основного закона) - собственное управление. В данной сфере земли сами регулируют создание ведомств и процедуры управления. При этом, если федеральными законами не предусмотрено иное, земли могут принимать отклоняющиеся правила. Кроме того, в исключительных случаях, из-за особой необходимости, Федерация сама может законодательно регулировать административные процедуры без предоставления такого права землям (абзац 1 статьи 84). Федерация обладает правом надзора за выполнением федеральных законов землями в соответствии с действующим правом. С этой целью Федеральное правительство может согласия Бундесрата давать общие административные инструкции землям, направлять уполномоченных в высшие ведомства земель, а с их согласия или в случае их отказа с согласия Бундесрата — также в подчиненные им ведомства (абзац 3 статьи 84) и др.; 2) исполнение землями своих собственных законов; 3) исполнение федеральных законов по поручению Федерации (статьи 85, 87b, 89, 90 и др.). Данный тип управления возможен исключительно в областях, предусмотренных или допускаемых Основным законом. Речь, в частности, идет об управлении федеральными дорогами, водными путями, о финансовом управлении и т.д. В случае управления по поручению Федерации создание ведомств остается делом земель, поскольку федеральные законы с одобрения Бундесрата не устанавливают иного. Однако федеральное правительство может издавать с одобрения Бундесрата общие административные предписания и регулировать подготовку служащих и чиновников на единых началах.

${ }^{17}$ См. подробнее: Фосскуле $A$. Система исполнительной власти в Федеративной Республике Германия //Конституционное право: Восточноевропейское обозрение. - 2004. - № 1. - С. 82.
Органы земель подчиняются указаниям компетентных высших органов Федерации. Такие указания передаются высшим ведомствам земель, кроме случаев, признаваемых Федеральным правительством срочными. Выполнение указаний должны обеспечивать высшие ведомства земель. В отличие от надзора за собственным управлением земель согласно статье 84 Основного закона, федеральные надзорные полномочия в сфере управления по поручению распространяется не только на законность, но также и на целесообразность исполнения (статья 85). Федеральное правительство также может с целью надзора требовать отчета и представления документов и направления уполномоченных во все ведомства; 4) исполнение федеральных законов Федерацией в случаях, предусмотренных или допускаемых Основным законом (статьи 86-91). Речь идет о таких полномочиях, как управление внешними сношениями, управление федеральными финансами, Вооруженные силы, воздушное сообщение, железнодорожное сообщение и др.; 5) смешанное управление (статьи 91a, 91b, 91с Основного закона). К совместным задачам Федерации и земель Конституция отнесла следующее: улучшение региональной экономической структуры (Федерация финансирует половину расходов в каждой земле); улучшение аграрной структуры и защиту береговой линии (Федерация возмещает не менее половины расходов; регулирование участия должно быть единым для всех земель) (статья 91а). Кроме того, возможно также сотрудничество на основе соответствующих соглашений в области образовательных программ и содействия научным исследованиям, а также в области планирования, строительства, и эксплуатации информационно-технологических систем (статьи 91b и 91с).

В институциональном разрезе Федерация в Германии не имеет общих органов управления (за исключением канцелярии Федерального канцлера), наделенных компетенцией в широкой сфере деятельности, существуют только специальные органы, как правило, не имеющие подчиненных структур или подразделений. Федеральные органы средней и нижней компетенции существуют лишь в немногочисленных областях, указанных в самом Основном законе (в соответствии с абзацами 1 и 3 статьи 87 в непосредственное федеральное управление $с$ собственными подчиненными ему административными органами входят управление внешними сношениями, управление федеральными финансами и управление федеральными водными путями и судоходством, а вопросам исключительной законодательной компетенции Федерации также в случае настоятельной необходимости разрешается учреждение федеральных органов власти средней или нижней ступени).

При реализации модели исполнительного федерализма центральные исполнительные органы имеют достаточно ограниченный аппарат на местах, численность которого 


\section{Право и политика $2(158) \cdot 2013$}

зависит от объема вопросов по исключительным предметам ведения федерации. Основная нагрузка по исполнению федерального законодательства ложится на региональные властные структуры ${ }^{18}$. Как отмечает А. Фосскуле, в данном случае речь идет об обычной рационализации управления, поскольку с экономической точки зрения целесообразнее использовать земельный исполнительный аппарат и для исполнения федеральных законов и не создавать параллельных территориальных структур федеральных органов. Кроме того, с позиций децентрализованной концепции исполнительной власти сильная исполнительная власть субъектов федерации создает противовес, баланс неизбежно существующим тенденциям концентрации власти на федеральном уровне ${ }^{19}$.

В соответствии с Федеральным конституционным законом Австрии 1920 года выделяются следующие вопросы, по которым: 1) Федерация осуществляет законодательную и исполнительную власть (например, статья 10); 2) Федерация имеет законодательную власть, а земли - исполнительную (статья 11); 3 ) Федерация устанавливает общие принципы, а земли издают конкретизирующие законы и осуществляют исполнительную деятельность (статья 12); 4) земли осуществляют законодательную и исполнительную деятельность (абзац 4 статьи 14, статья $15)^{20}$. По общему правилу в Австрии Федерация осуществляет свою исполнительную власть в землях через губернатора земли и подчиненные ему органы (непрямое федеральное управление) (статья 102). При этом по вопросам непрямого федерального управления губернатор связан указаниями Федерального правительства, а также отдельных федеральных министров (статья 103). Федеральные указания направляются губернатору, а последний, если он самостоятельно не осуществляет соответствующие полномочия передает их компетентному члену правительства земли и следит за осуществлением указаний. Кроме того, по вопросам, относящимся к непрямому федеральному управлению, Губернатор несет перед Федеральным правительством ответственность (статьи 105 и142).

Идея реализации в России положительно зарекомендовавшего себя в зарубежных странах принципа исполнительного федерализма созвучна с высказывавшейся в

\footnotetext{
${ }^{18}$ Следует отметить, что данное обстоятельство тем более имеет актуальное значение для современного российского государства в связи с осуществляемой политикой сокращения численности федеральных государственных гражданских служащих в соответствии с Указом Президента России от 31 декабря 2010 года № 1657 «Об оптимизации численности федеральных государственных гражданских служащих и работников федеральных государственных органов».

${ }^{19}$ См.: Фосскуле А. Указ. соч. С. 85.

${ }^{20}$ См.: Федеральный конституционный закон от 10 ноября 1920 года. URL: http://www.concourt.am/armenian/legal_resources/world_constitutions/constit/austria/Austria4.html.
}

научной литератур точкой зрения о том, что управление в ряде сфер общественной жизни должно строиться «по принципу, хорошо нам известному с советских времен и получившему название «двойного подчинения.» ${ }^{21}$. Указанный принцип в советский период означал двойное подчинение исполнительных комитетов соответствующим Советам, которыми они избирались и были призваны проводить в жизнь решения последних, а также вышестоящему исполнительному комитету или Совету Министров. Как справедливо отмечает профессор Авакьян С.А., субъекты федерации не случайно относительно спокойно пошли на реальное назначение главы исполнительной власти субъекта Президентом России, поскольку надеялись, что глава государства передаст губернаторам возможности контроля и координации в отношении подразделений центра в субъектах $Р \Phi^{22}$.

Таким образом, думается, что с учетом вышеизложенного в Российской Федерации сложились все предпосылки (исторические традиции «двойного подчинения» советского периода и современная тенденция централизации государственной власти) для реализации в практике деятельности публичной власти принципа исполнительного федерализма. Более того, внедрение данного принципа не потребует внесения изменений непосредственно в Конституцию 1993 года. Нормы Основного закона достаточно широки и вполне согласуются в принципиальных аспектах с концепцией исполнительного федерализма, поскольку не содержат разделения федеральных и региональных исполнительных полномочий в рамках статьи 72, перечисляющей предметы совместного ведения.

В научной литературе была высказана точка зрения о существовании в России модели раздельного управления. «Сопоставление содержания ст. 73 и ч. 2 ст. 77 Конституции свидетельствует лишь о конституционно обозначенной границе между единой системой исполнительной власти в Российской Федерации и исполнительной властью в субъектах Российской Федерации. ... Единство системы исполнительной власти выражается лишь в том, что акты главы государства и акты федерального Правительства (в пределах федерального ведения и полномочий Российской Федерации по предметам совместного ведения) столь же обязательны для органов исполнительной власти субъектов Российской Федерации, как они обязательны для федеральных

\footnotetext{
${ }^{21}$ См.: Авакьян С.А. Проблемы централизма, демократии, децентрализации в современном государстве: конституционноправовые вопросы /Централизм, демократия, децентрализация в современном государстве: конституционно-правовые вопросы. Материалы международной научной конференции. Москва, 7-9 апреля 2005 года. - М.: ТК Велби, 2006. С. 10.

22 Там же.
} 
Государственные институты и правовые системы

министерств и ведомств (и их территориальных органов).» $»^{23}$. Думается, вопрос о существовании той или иной модели распределения исполнительной власти по вертикали (смешанная или раздельная) оставлен открытым в Конституции 1993 года. В связи с этим конкретизация конституционных положений должна осуществляться в рамках текущего законодательства.

Опыт Германии с раздельной исполнительной властью с позволяет наметить определенные ориентиры для развития в России принципов исполнительного федерализма. Подтверждением такой возможности, помимо вышесказанного, являются следующие конституционные и законодательные положения: 1) возможность, а не императивность создания территориальных органов федеральных органов исполнительной власти (часть 1 статьи 78 Конституции Российской Федерации); 2) подконтрольность региональных органов исполнительной власти Правительству России в соответствии со статьей 44 Федерального конституционного закона от 17 декабря 1997 года № 2-ФКЗ «О Правительстве Российской Федерации». Правительство России в пределах своих полномочий осуществляет контроль за деятельностью органов исполнительной власти субъектов Федерации по вопросам, отнесенным к ведению Российской Федерации и полномочиям Российской Федерации по предметам совместного ведения Российской Федерации и субъектов Российской Федерации ${ }^{24}$. В данном случае хотя соответствующий контроль и является консультативным (а не постановляющим ${ }^{25}$, все же сфера его осуществления - предметы ведения Федерации и полномочия России по предметам совместного ведения - позволяют разделить законодательную и исполнительную деятельность по вертикали. При этом механизм контроля, закрепленный в указанной норме, в принципиальных моментах аналогичен процедуре контроля, предусмотренной статьей 84 Основного закона Германии (за тем исключением, окончательное решение по вопросу противоречия актов региональных органов исполнительной власти федеральному праву принимает не орган представительства субъектов Федерации - Совет Федерации, а соответствующий суд). Кроме того, ничто не препятствует включению в текст федерального закона в рамках распределения совместной компетенции положений о возможности

${ }^{23}$ См., например: Филиппова Н.А. Исполнительный федерализм в России: выбор между внепарламентской и парламентской моделями обеспечения интересов субъектов Федерации //Конституционное и муниципальное право. - 2008. - № 15. СПС «Консультант Плюс».

${ }^{24}$ См.: Собрание законодательства РФ. - 1997. - № 51, ст. 5712.

${ }^{25}$ См. подробнее: Филиппова Н.А. Указ. соч. СПС «Консультант Плюс». дачи федеральным Правительством общих предписаний и (или) конкретных указаний по его исполнению.

Следует поддержать позицию Филипповой Н.А. о сходстве российской модели федерализма с канадской в части возможности заключения соглашений о взаимной передаче исполнительной компетенции ${ }^{26}$. Тем не менее, не следует возможность заключения указанных соглашений интерпретировать исключительно как проявление дуалистического характера отечественных федеративных отношений. Российская модель территориального устройства не может и не должна абсолютно копировать существующие зарубежные образцы.

В связи с этим полагаем, что нельзя однозначно квалифицировать российскую конституционную модель исполнительной власти как дуалистическую или кооперативную. Соответствующая конституционная конструкция является во многом фрагментарной, не предопределяющей конкретные направления дальнейшей его конкретизации в текущем законодательстве. Следовательно, потенциал указанных положений в настоящее время далеко не исчерпан, и нуждается в законодательной реализации, предпочтительным вариантом которой является европейская концепция «исполнительного федерализма».

В данном контексте интерес представляет толкование принципа «единства исполнительной власти», указанного в части 2 статьи 77 Конституции Российской Федерации. По указанному вопросу существуют несовпадающие позиции, что опять-таки свидетельствует о недосказанности самого Основного закона по данному поводу. Так, было высказано мнение о том, что исходя из смысла части 2 статьи 77 и статьи 78 вытекает следующее:

- в контексте предметов исключительного ведения Федерации и ее субъектов имеются отдельные системы исполнительной власти, при этом возможна передача соответствующих полномочий;

- в контексте вопросов совместного ведения существует единая исполнительная вертикаль ${ }^{27}$. При этом подчеркивается, что в статье 78 Конституции речь идет только об осуществлении или передаче исключительных полномочий Федерации и ее субъектов.

Думается, единство исполнительной системы в России обусловлено пределами законодательной компетенции Федерации, т.е. законодательной сферой исключительных предметов ведения и законодательными полномочиями в рамках совместных предметов ведения. В этом смысле статья 78 Основного закона предполагает

\footnotetext{
${ }^{26}$ См.: Там же.

${ }^{27}$ См. подробнее: Бланкенагель $A$. Концепция единой системы исполнительной власти, часть 2 статьи 77 Конституции Российской Федерации - где система, а где единство //Сравнительное конституционное обозрение. - 2006. - № 1. СПС «КонсультантПлюс».
} 


\section{Право и политика 2 (158) 2013}

распределение любых исполнительных полномочий различных уровней государственной власти, в том числе ранее в законодательном или договорном порядке разграниченных предметов совместного ведения. Кроме того, следует учитывать, что в указанных конституционных положениях говорится о передаче полномочий именно государственных исполнительных органов. Полномочия последних производны от разграничения предметов совместного ведения Федерации и ее субъектов. Таким образом, единство исполнительной власти в России функционально связано с разграничением законодательных полномочий по вертикали. Тем не менее, в институциональном аспекте данное обстоятельство не влияет на возможность несовпадения субъектов реализации законодательной и исполнительной компетенции по одному тому же вопросу.

С учетом вышеизложенного, вполне справедливым представляется постановка задачи: установление равновесия между концепцией «единства исполнительной власти» и идеей федерализма, предполагающей существование двух отдельных систем исполнительной власти ${ }^{28}$. Можно предложить следующие схемы организации исполнительной власти по вертикали в Российской Федерации и соответствующие им сферы законодательной компетенции:

Федеральное управление в регионах путем создания территориальных органов исполнительной власти. При этом высшее должностное лицо субъекта имеет право ограниченного контроля за деятельностью указанных органов (исключительные предметы ведения Федерации);

Федеральное управление в регионах путем создания территориальных органов исполнительной власти с предоставлением высшим должностным лицам субъектов Федерации права согласования и дачи поручений - принцип «двойного подчинения» (исключительные предметы ведения Федерации и часть совместных предметов ведения, в рамках которых регионы обладают ограниченным законодательными полномочиями);

Исполнение субъектами федеральных законов как своих с предоставлением Федерации в лице Президента и Правительства издавать общие административные предписания и давать конкретные поручения (предметы совместного ведения, рамках которых Федерация принимает рамочное законодательство, устанавливает общие принципы, а субъекты Федерации - издают конкретизирующие, всеобъемлющие акты);

Исполнение регионами своего собственного законодательства (исключительные предметы ведения субъектов Федерации).

${ }^{28}$ См.: Бланкенагель А. Указ. соч. СПС «КонсультантПлюс».

\section{Библиография:}

1. Андерсон Дж. Федерализм: введение. М.: Экономика, 2009. 127c.

2. Цвайгерт К., Кётц Х. Введение в сравнительное правоведение в сфере частного права: В 2-х тт. Том I. Основы: Пер. с нем. - М.: Международные отношения, 2000. 480 c.

3. Филиппова Н.А. Исполнительный федерализм в России: выбор между внепарламентской и парламентской моделями обеспечения интересов субъектов Федерации //Конституционное и муниципальное право. 2008. № 15. С. 22-29.

4. Саленко А.В. Федерализм в России и Германии: Сравнительный анализ: Автореферат диссертации на соискание ученой степени кандидата юридических наук. - М., 2002. 36 с.

5. Фляйнер Т. Швейцария: субсидиарность, этническое и культурное разнообразие //Материалы Международной научно-практической конференции «Федерализм: российское и швейцарское измерения» (Казань, 22-23 июня 2001года). URL: http://www. kazanfed.ru/actions/konfer2/.

6. Фосскуле А. Система исполнительной власти в Федеративной Республике Германия //Конституционное право: Восточноевропейское обозрение. 2004. № 1. C. 81-92.

7. Авакьян С.А. Проблемы централизма, демократии, децентрализации в современном государстве: конституционно-правовые вопросы /Централизм, демократия, децентрализация в современном государстве: конституционно-правовые вопросы. Материалы международной научной конференции. Москва, 7-9 апреля 2005 года. - М.: ТК Велби, 2006. С. 4-13.

8. Бланкенагель А. Концепция единой системы исполнительной власти, часть 2 статьи 77 Конституции Российской Федерации - где система, а где единство //Сравнительное конституционное обозрение. 2006. № 1. С. 123-128.

9. Люхтерхандт О. Россия на пути к имитации федерализма //Казанский федералист. 2005. № 2-3(1415). URL: http://www.kazanfed.ru/publications/ kazanfederalist/n14-15/29/.

10. Бланкенагель А. В поисках исчезнувших исключительных полномочий субъектов Российской Федерации //Сравнительное конституционное обозрение. 2007. № 1. С. 153-162.

\section{References (transliteration):}

1. Anderson Dzh. Federalizm: vvedenie. M.: Ekonomika, 2009. 127s. 
2. Tsvaygert K., Ketts X. Vvedenie v sravnitel'noe pravovedenie $\mathrm{v}$ sfere chastnogo prava: V 2-kh tt. - Tom I. Osnovy: Per. s nem. - M.: Mezhdunarodnye otnosheniya, 2000. $480 \mathrm{~s}$.

3. Filippova N.A. Ispolnitel'nyy federalizm v Rossii: vybor mezhdu vneparlamentskoy i parlamentskoy modelyami obespecheniya interesov sub'ektov Federatsii //Konstitutsionnoe i munitsipal'noe pravo. 2008. № 15. S. 22-29.

4. Salenko A.V. Federalizm v Rossii i Germanii: Sravnitel'nyy analiz: Avtoreferat dissertatsii na soiskanie uchenoy stepeni kandidata yuridicheskikh nauk. - M., 2002. 36 s.

5. Flyayner T. Shveytsariya: subsidiarnost', etnicheskoe i kul'turnoe raznoobrazie //Materialy Mezhdunarodnoy nauchno-prakticheskoy konferentsii «Federalizm: rossiyskoe i shveytsarskoe izmereniya» (Kazan', 22-23 iyunya 2001goda). URL: http://www.kazanfed.ru/actions/konfer2/.

6. Fosskule A. Sistema ispolnitel'noy vlasti v Federativnoy Respublike Germaniya//Konstitutsionnoe pravo: Vostochnoevropeyskoe obozrenie. 2004. № 1. S. 81-92.
7. Avak'yan S.A. Problemy tsentralizma, demokratii, detsentralizatsii v sovremennom gosudarstve: konstitutsionno-pravovye voprosy /Tsentralizm, demokratiya, detsentralizatsiya v sovremennom gosudarstve: konstitutsionno-pravovye voprosy. Materialy mezhdunarodnoy nauchnoy konferentsii. Moskva, 7-9 aprelya 2005 goda. - M.: TK Velbi, 2006. S. 4-13.

8. Blankenagel' A. Kontseptsiya edinoy sistemy ispolnitel'noy vlasti, chast' 2 stat'i 77 Konstitutsii Rossiyskoy Federatsii - gde sistema, a gde edinstvo //Sravnitel'noe konstitutsionnoe obozrenie. 2006. № 1. S. 123-128.

9. Lyukhterkhandt O. Rossiya na puti k imitatsii federalizma //Kazanskiy federalist. 2005. № 2-3(14-15). URL: http://www.kazanfed.ru/publications/kazanfederalist/n14-15/29/.

10. Blankenagel' A. V poiskakh ischeznuvshikh isklyuchitel'nykh polnomochiy sub'ektov Rossiyskoy Federatsii //Sravnitel’noe konstitutsionnoe obozrenie. 2007. № 1. S. 153-162. 